\title{
ATP-binding cassette transporters in primary central nervous system lymphoma: Decreased expression of $M D R 1$ P-glycoprotein and breast cancer resistance protein in tumor capillary endothelial cells
}

\author{
SEIJI SAKATA ${ }^{1}$, MASACHIKA FUJIWARA ${ }^{1}$, KOUKI OHTSUKA ${ }^{2}$, HIROSHI KAMMA $^{1}$, \\ MOTOO NAGANE $^{3}$, ATSUHIKO SAKAMOTO ${ }^{1}$ and YASUNORI FUJIOKA ${ }^{1}$ \\ Departments of ${ }^{1}$ Pathology, ${ }^{2}$ Laboratory Medicine and ${ }^{3}$ Neurosurgery, \\ Kyorin University Faculty of Medicine, 6-20-2 Shinkawa, Mitaka, Tokyo 181-8611, Japan
}

Received July 27, 2010; Accepted September 25, 2010

DOI: 10.3892/or.2010.1102

\begin{abstract}
Most tumors in the central nervous system are drug resistant partly because of the presence of the bloodbrain barrier (BBB) between circulating blood and tumor tissues. Primary central nervous system lymphoma (PCNSL) is one of the exceptions, as it is highly sensitive to high-dose methotrexate (MTX)-based chemotherapy. The aim of this study was to evaluate the BBB function of tumor capillary endothelial cells in PCNSL. Expression of three major drug efflux transporters that belong to the ATP-binding cassette (ABC) superfamily, P-glycoprotein encoded by the human multidrug resistance gene (MDRl Pgp; ABCB1), breast cancer resistance protein (BCRP; ABCG2), and multidrug resistance-associated protein 1 (MRP1; ABCC1), was evaluated. Immunohistochemistry was performed in capillary endothelial cells of 30 tumor areas from 22 PCNSL cases and compared with that of 30 gliomas. The microenvironment around tumor capillaries was assessed by examining the distribution of astrocytes and by counting the number of macrophages and T-cells, the principal cytokine producers. In PCNSL, expression of MDRI Pgp and BCRP in tumor capillary endothelial cells was decreased in 63 and $93 \%$ of tumor areas examined, respectively, and these reduction levels differed significantly from those of gliomas $(\mathrm{P}<0.05)$. When the PCNSLs were further segregated by way of infiltration of tumor cells into three patterns (dense, perivascular and sparse), decreased MDRI Pgp and BCRP in tumor capillary endothelial cells were much more prominent in dense and
\end{abstract}

Correspondence to: Dr Masachika Fujiwara, Department of Pathology, Kyorin University Faculty of Medicine, 6-20-2 Shinkawa, Mitaka, Tokyo 181-8611, Japan

E-mail: masachi@ks.kyorin-u.ac.jp

Key words: Primary central nervous system lymphoma, ABC transporter, MDRl Pgp, BCRP, endothelial cells perivascular patterns. In all tumors and non-tumor areas of the brain, MRP1 was undetected on capillary endothelial cells. Assessment of the microenvironment around the tumor capillaries suggested that dissociation from astrocytes and infiltration of macrophages and T-cells was involved in the down-regulation of MDRl Pgp and BCRP in capillary endothelial cells. In conclusion, we report that expression of the major ABC transporters of the BBB, MDRl Pgp and BCRP, decreases in tumor capillary endothelial cells of PCNSL. Thus, decreased expression may permit delivery of chemotherapeutic agents to the tumor tissues.

\section{Introduction}

Primary central nervous system lymphoma (PCNSL) occurs in the cranial axis without evidence of systemic involvement, and it accounts for $2.7 \%$ of all malignant diseases of the central nervous system (CNS). Approximately $90 \%$ of PCNSL are diffuse large B-cell type (1). Unlike other CNS tumors, PCNSL often shows a favorable response to chemotherapy. The majority of the active regimens include the use of highdose methotrexate (HD-MTX), which has become a standard component in the treatment of PCNSL (2-5).

The blood-brain barrier (BBB) limits CNS delivery of many chemotherapeutic agents. The BBB is composed of capillary endothelial cells, which are sealed by tight junctions and surrounded by astrocyte foot processes and pericytes. In physiologic conditions of the BBB, capillary endothelial cells express multidrug integral membrane proteins that translocate solutes across cellular membranes by use of energy of ATP hydrolysis. These proteins belong to the members of the ATP-binding cassette (ABC) superfamily, which includes $\mathrm{P}$-glycoprotein encoded by the human multidrug resistance gene (MDR1 Pgp; ABCB1), breast cancer resistance protein (BCRP; ABCG2), and multidrug resistance-associated protein 1 (MRP1; ABCC1) (6-8). The ABC transporters play an important role in drug efflux and limit the ability of many drugs to access the CNS. Some studies have demonstrated that MTX is one of the substrate drugs excreted by ABC transporters such as MDRl Pgp, BCRP and MRP1 (9-11). 
Although the mechanism of $\mathrm{BBB}$ regulation remains to be elucidated, recent studies have shown that BBB function is influenced by the microenvironment around the capillaries, which consists of elements such as astrocytes and proinflammatory cytokines (12-16).

Tóth et al reported that MDRl Pgp is expressed in tumor capillary endothelial cells of gliomas and some metastatic brain tumors. The authors suggested that multidrug resistance of these brain tumors may result not only from the expression of resistance markers in neoplastic cells but also from their expression in endothelial cells of tumor capillaries (17). To our knowledge, in PCNSL, expression of ABC transporters in tumor capillary endothelial cells has not been investigated to date. Thus, this paucity of information prompted us to assess the expression of three major ABC transporters, MDRl Pgp, BCRP, and MRP1, in capillary endothelial cells of PCNSL by immunohistochemistry.

\section{Materials and methods}

Specimens. Archival samples from 22 cases of PCNSL were retrieved from the database of the Kyorin University Hospital, Tokyo. The archival cases were diagnosed and treated between 2001 and 2009. No human immunodeficiency virusinfected patients were included in this study. The slides were reviewed and an appropriate block was selected from each case. All tissues were routinely fixed in $10 \%$ formalin and embedded in paraffin wax. To create a representative group for comparison in immunohistochemistry, tissues from 30 glioma cases diagnosed at Kyorin University Hospital between 2006 and 2009 were also selected. Histological types and grades of PCNSL as well as glioma specimens were independently re-evaluated by two pathologists (S.S. and M.F.) according to the World Health Organization Classification of Tumours of the Central Nervous System, 4th edition (18).

Classification of PCNSL histological patterns and grading of gliomas. In this study, histology of PCNSL was segregated by way of infiltration of the tumor cells into three patterns: dense, perivascular, and sparse. The dense pattern implies diffuse proliferation of tumor cells, which infiltrate closely to one another without intermingling with neuronal or glial fibers. The perivascular pattern is characterized by angiocentric infiltration of tumor cells in the form of typical perivascular cuffs (arbitrarily defined as five or more layers of tumor cells). The sparse pattern indicates a scattering of tumor cells that singly infiltrate the brain parenchyma and resemble encephalitis.

PCNSL often shows heterogeneity within a tumor, disposing the latter two patterns (perivascular and sparse) around the periphery (1). Therefore, the pattern observed in each tissue sample might reflect the local aspect of the tumor rather than the manifestation of its entire histological characteristics. In cases harboring areas of two or more different patterns of infiltration, we decided to evaluate each area separately by immunohistochemistry. Thus, we assessed up to 30 tumor areas from 22 PCNSL cases.

We divided the glioma tissues into low and high grades. Low-grade glioma corresponds to grades I and II and high-grade glioma corresponds to grades III and IV in the four-tiered grading system of WHO (18). Microvascular proliferation is one of the essential diagnostic criteria for distinguishing high-grade gliomas from low-grade gliomas. Histological patterns and grades of the tumors were evaluated on hematoxylin-eosin-stained sections.

Immunohistochemistry. For immunohistochemical analysis, the following primary antibodies were used: anti-MDR1 Pgp mouse monoclonal antibody (clone JSB-1, dilution 1:400; Santa Cruz Biotechnology, Santa Cruz, CA, USA), antiBCRP mouse monoclonal antibody (clone BXP21, dilution 1:4000; Kamiya Biomedical, Seattle, WA, USA), anti-MRP1 mouse monoclonal antibody (clone MRPm6, dilution 1:50; Kamiya Biomedical), anti-Glial Fibrillary Acid Protein (GFAP) rabbit polyclonal antibody (dilution 1:8; Nichirei Bioscience, Tokyo, Japan), anti-CD20 mouse monoclonal antibody (clone L26, dilution 1:100; DakoCytomation, Glostrup, Denmark), anti-CD3 mouse monoclonal antibody (clone PS1, dilution 1:100; Novocastra, Newcastle, UK), anti-CD68 mouse monoclonal antibody (clone PGM-1, dilution 1:100; DakoCytomation), and anti-CD31 mouse monoclonal antibody (clone JC70A, dilution 1:25; DakoCytomation).

Paraffin-embedded tissues were cut at a thickness of $4 \mu \mathrm{m}$. The sections were then deparaffinized in xylene, rehydrated in ethanol solution, and soaked in $3 \% \mathrm{H}_{2} \mathrm{O}_{2}$ in methanol for $15 \mathrm{~min}$ to inactivate endogenous peroxidase. Sections for CD68 staining were pretreated with proteinase $\mathrm{K}$ for $5 \mathrm{~min}$ at room temperature. The sections for MDRl Pgp, BCRP, MRP1 and CD20 were placed in an autoclave and heated for $15 \mathrm{~min}$ at $121^{\circ} \mathrm{C}$ in citrate buffer ( $\mathrm{pH} \mathrm{6.0)}$ ), or in EDTA (pH 9.0) for CD3 and CD31. After proteinase pretreatment or heating, the sections were rinsed in Tris-HCl buffer ( $\mathrm{pH}$ 7.6) at room temperature for $5 \mathrm{~min}$. Sections were incubated with each primary antibody overnight at $4^{\circ} \mathrm{C}$. For antibody detection, we used Acuity Detection System (Signet Laboratories, Dedham, MA, USA; Cat No. 2606) for antiMDR1, anti-BCRP and anti-MRP1. The EnVision Detection Kit (DakoCytomation; Cat No. K5007) was used for GFAP, CD3, CD20, CD68 and CD31. The sections were counterstained with Mayer's hematoxylin.

Evaluation of ABC transporter expression in tumor capillary endothelial cells and tumor cells. Following confirmation of capillary distribution in the tumors stained with anti-CD31, the intensity of staining for MDR1, BCRP and MRP1 was scored from 0 to $2+$ against capillaries in non-tumor brain tissue that served as the control. The scores were as follows: 0 , absent; $1+$, weaker intensity than capillaries in the nontumor brain; and $2+$, comparable intensity to capillaries in the non-tumor brain. In tumors with areas of two or more different scores, the predominant areas were used as the representatives.

Drug resistance of tumor cells is reported to be associated with their own ability to express ABC transporters. Therefore, we also evaluated the immunoreactivities of each $\mathrm{ABC}$ transporter in the tumor cells by scoring 0 to $3+$ as follows: 0 , absent; $1+,<5 \%$ tumor cells reactive; $2+, 5-25 \%$ tumor cells reactive or $>25 \%$ tumor cells reactive at a weaker intensity than capillaries in the non-tumor brain; $3+,>25 \%$ tumor cells 

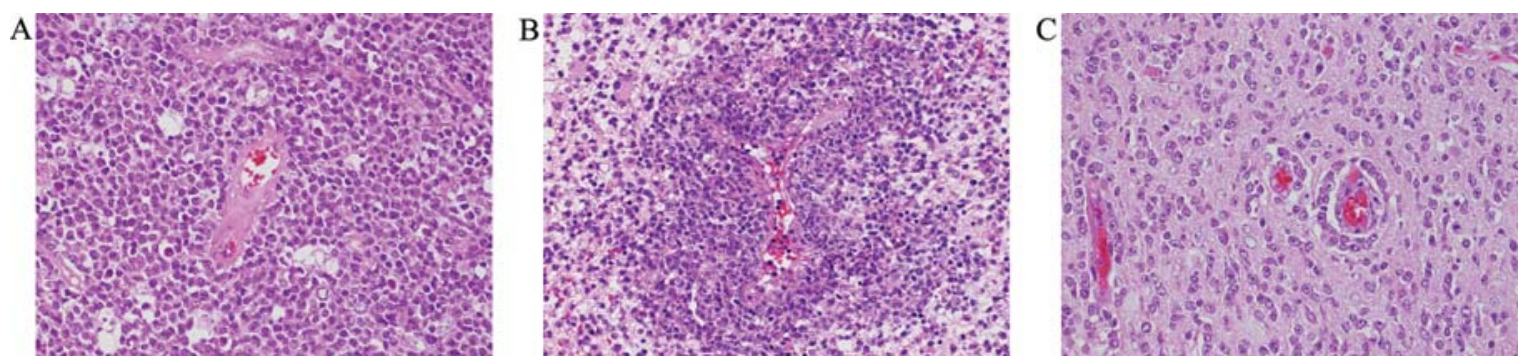

Figure 1. The representative images of three histological types of PCNSL (hematoxylin-eosin stain). (A) Dense pattern; (B) perivascular pattern; (C) sparse pattern. Magnification, x200.

reactive at a comparable intensity to capillaries in the nontumor brain.

Assessment of the microenvironment around the tumor capillaries. For each PCNSL and glioma sample, the distribution of astrocytes and their foot processes, either nonneoplastic or neoplastic, were examined on sections stained with anti-GFAP antibody.

In addition, to predict the influence of pro-inflammatory cytokines such as interleukins and tumor necrosis factor- $\alpha$ $(\mathrm{TNF}-\alpha)$ on the expression of ABC transporters in tumor capillary endothelial cells, we counted the number of principal cytokine producers, the macrophages and T-cells, around the capillaries. CD68- and CD3-stained sections were used for counting macrophages and T-cells, respectively. We determined the average value of three representative fields at x200 magnification in each subject.

Statistical analysis. Staining data were analyzed using statcel software (OMS, Tokorozawa, Japan). Mann-Whitney U-test was applied to determine the difference in immunohistochemical scores for the expression of $\mathrm{ABC}$ transporters in tumor capillary endothelial cells, and in the numbers of CD68positive macrophages and CD3-positive T cells around the tumor capillaries. P-values of $<0.05$ were considered statistically significant.

\section{Results}

Classification of PCNSL histological patterns and grading of glioma. Re-evaluation of the PCNSL samples by histology and immunohistochemistry for CD20 confirmed that all cases studied were of the diffuse large B-cell type. Of 30 areas from 22 cases of PCNSL, 11 were classified as having a dense pattern, 7 a perivascular pattern, and 12 a sparse pattern. Fig. 1 shows the representative areas of these three patterns. Of 30 glioma cases, 9 were categorized as low grade and 21 as high grade.

Expression of $A B C$ transporters in tumor capillary endothelial cells. Immunohistochemical analysis of tumor capillary endothelial cells from PCNSL showed a decrease of MDRl Pgp in 19 (63\%) and BCRP in 28 (93\%) tumor areas (Table I). The decrease of BCRP was much more dramatic, as BCRP was undetectable in $50 \%$ of subjects. Concerning the three histological patterns of PCNSL, decreased amounts of MDRl Pgp and BCRP in the tumor capillary endothelial
Table I. Expression of ABC transporters in tumor capillary endothelial cells.

\begin{tabular}{lccc}
\hline & & \multicolumn{2}{c}{ Glioma $^{\mathrm{b}}$} \\
\cline { 3 - 4 } & $\begin{array}{c}\text { PCNSL } \\
(\mathrm{n}=30)(\%)\end{array}$ & $\begin{array}{c}\text { Low grade } \\
(\mathrm{n}=9)(\%)\end{array}$ & $\begin{array}{c}\text { High grade } \\
(\mathrm{n}=21)(\%)\end{array}$ \\
\hline $\begin{array}{l}\text { MDR1 Pgp } \\
2+\end{array}$ & $11(37)$ & $9(100)$ & $16(77)$ \\
$1+$ & $18(60)$ & $0(0)$ & $5(23)$ \\
0 & $1(3)$ & $0(0)$ & $0(0)$ \\
BCRP & & & \\
$2+$ & $2(7)$ & $9(100)$ & $23(77)$ \\
$1+$ & $13(43)$ & $0(0)$ & $5(23)$ \\
0 & $15(50)$ & $0(0)$ & $0(0)$ \\
MRP1 & & & $0(0)$ \\
$2+$ & $0(0)$ & $0(0)$ & $0(0)$ \\
$1+$ & $0(0)$ & $0(0)$ & $21(100)$ \\
0 & $30(100)$ & $9(100)$ & \\
\hline
\end{tabular}

PCNSL, primary central nervous system lymphoma. Immunoreactivity was scored as: 0 , absent; $1+$, weaker intensity than capillaries in the non-tumor brain; $2+$, comparable intensity to capillaries in the non-tumor brain. ${ }^{\mathrm{a}}$ vs. ${ }^{\mathrm{b}}, \mathrm{P}<0.05$, for each $M D R 1$ Pgp and BCRP.

cells were prominent in dense and perivascular areas compared to areas of sparse patterns (Table II). In contrast, most glioma cases were found to express MDRl Pgp and BCRP in the tumor capillary endothelial cells the same as in normal brain (Table I). Interestingly, in 5 high-grade gliomas, endothelial cells of proliferating microvasculatures and endothelial cells of capillaries around necrotic foci revealed decreased expression of MDRl Pgp and BCRP. The expression scores of MDRl Pgp and BCRP differed significantly between PCNSL and glioma. In all tumors as well as the non-tumor areas of the brain, MRP1 was undetectable on tumor capillary endothelial cells. Fig. 2 illustrates representative features of immunohistochemistry for MDR1 Pgp (left column) and BCRP (center column) in PCNSL (first to third row, 3 histological patterns), glioma (fourth row, high grade), and normal brain (bottom row). 


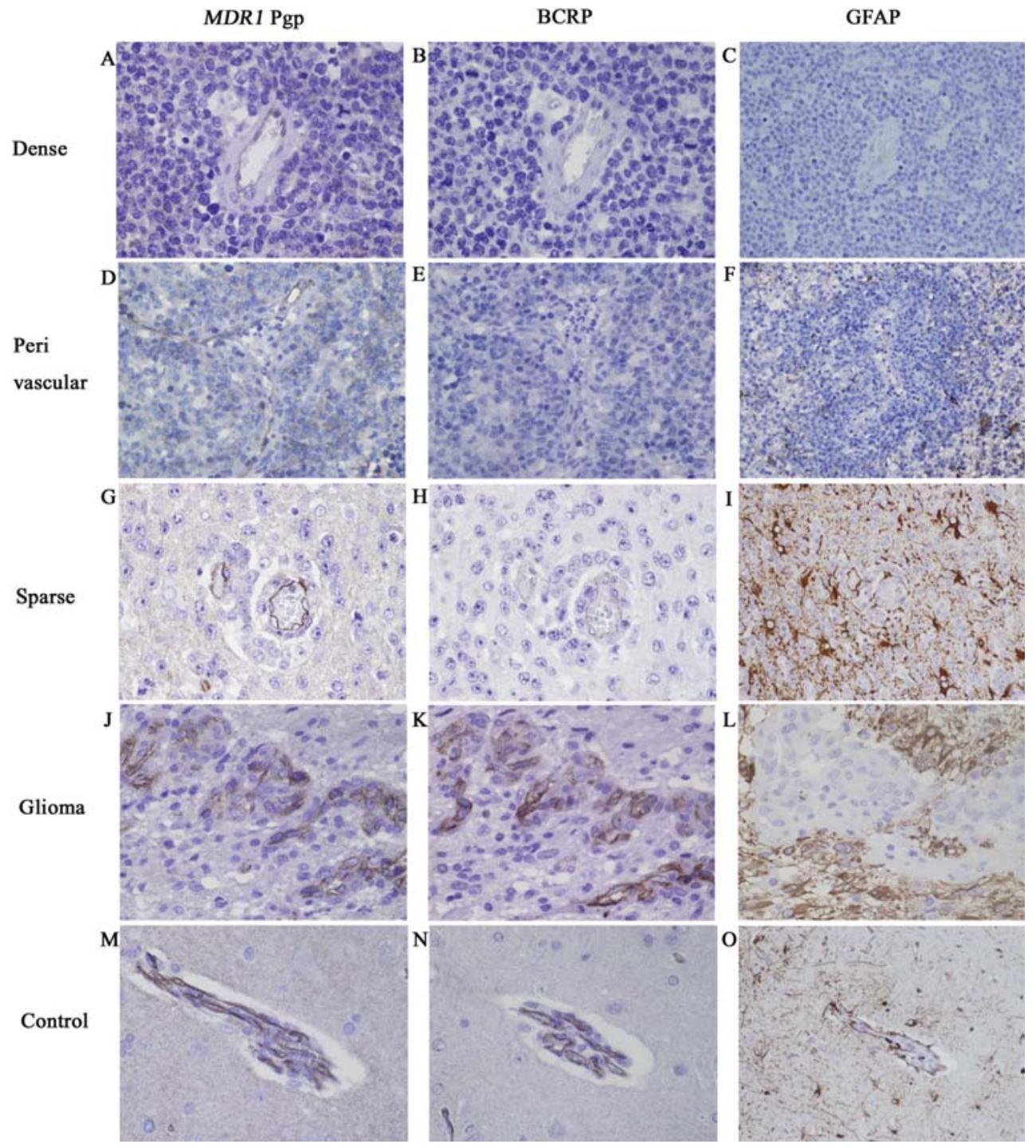

Figure 2. Immunohistochemistry of MDR1 Pgp, BCRP, and GFAP in three histological types of PCNSL (A-I), high-grade glioma (J-L), and normal brain (M-O). Expression of MDR1 Pgp and BCRP are decreased in dense and perivascular patterns of PCNSL (A and D, score 1+; B and E, score 0). Note: the absence of GFAP-positive astrocyte foot processes around the tumor capillaries in dense and perivascular regions of PCNSL (C and F). Magnification, x200 for MDR1 Pgp and BCRP, x100 for GFAP.

Table II. MDRl Pgp and BCRP expression in the tumor capillaries of three histological patterns of PCNSL.

\begin{tabular}{lccc}
\hline & $\begin{array}{c}\text { Dense }^{\mathrm{a}} \\
(\mathrm{n}=11)(\%)\end{array}$ & $\begin{array}{c}\text { Perivascular }^{\mathrm{a}} \\
(\mathrm{n}=7)(\%)\end{array}$ & $\begin{array}{c}\text { Sparse }^{\mathrm{b}} \\
(\mathrm{n}=12)(\%)\end{array}$ \\
\hline $\begin{array}{l}\text { MDRl Pgp } \\
2+\end{array}$ & $0(0)$ & $0(0)$ & $11(92)$ \\
$1+$ & $10(91)$ & $7(100)$ & $1(8)$ \\
0 & $1(9)$ & $0(0)$ & $0(0)$ \\
BCRP & & & \\
$2+$ & $0(0)$ & $0(0)$ & $2(17)$ \\
$1+$ & $2(18)$ & $1(14)$ & $10(83)$ \\
0 & $9(82)$ & $6(86)$ & $0(0)$ \\
\hline
\end{tabular}

Immunoreactivity was scored as: 0 , absent; $1+$, weaker intensity than capillaries in the non-tumor brain; $2+$, comparable intensity to capillaries in the non-tumor brain. ${ }^{\mathrm{a}} \mathrm{vs} .{ }^{\mathrm{b}}, \mathrm{P}<0.05$, for each $M D R 1$ Pgp and BCRP.
Distribution of astrocytes and their foot processes around the capillaries. Immunohistochemistry for GFAP implied that preservation of the astrocytes and their foot processes was apparently coupled with the expression of MDR I Pgp and BCRP in the tumor capillary endothelial cells (Fig. 2, right column). In sparse patterns of PCNSL with retained expression of MDRl Pgp and BCRP in the tumor capillary endothelial cells, the capillaries had contact with astrocyte foot processes. Conversely, in dense and perivascular patterns of PCNSL with significantly decreased or abolished expression of MDRI Pgp and BCRP in the tumor capillary endothelial cells, contact between the capillaries and the astrocytes was interrupted by infiltration of the tumor cells. Capillaries of both gliomas and normal brain had close contact with neoplastic and non-neoplastic astrocytes, respectively.

Number of macrophages and T-cells around the capillaries. Immunohistochemistry of CD68 and CD3 showed a manifestation of macrophages and T-cells intermingling with the 


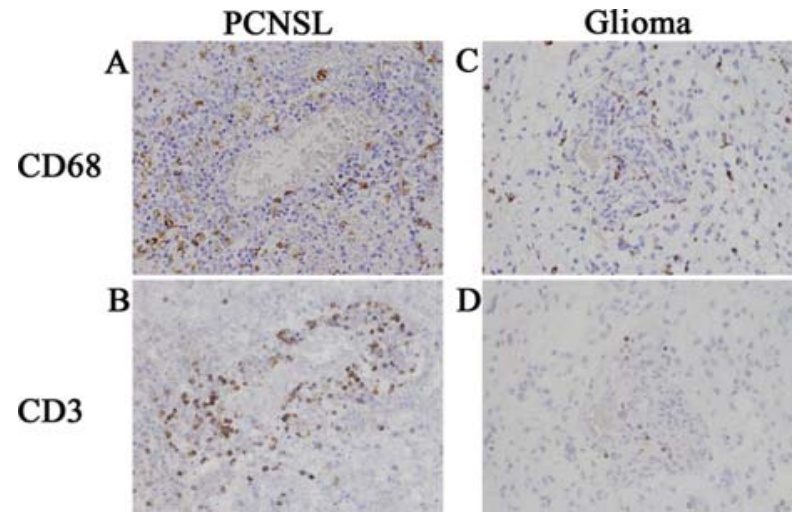

Figure 3. Immunohistochemistry of CD68 and CD3 in PCNSL (A and B) and high-grade glioma (C and D). A large number of macrophages and T-cells infiltrate around the tumor capillaries in PCNSL, compared to glioma. Magnification, x200.
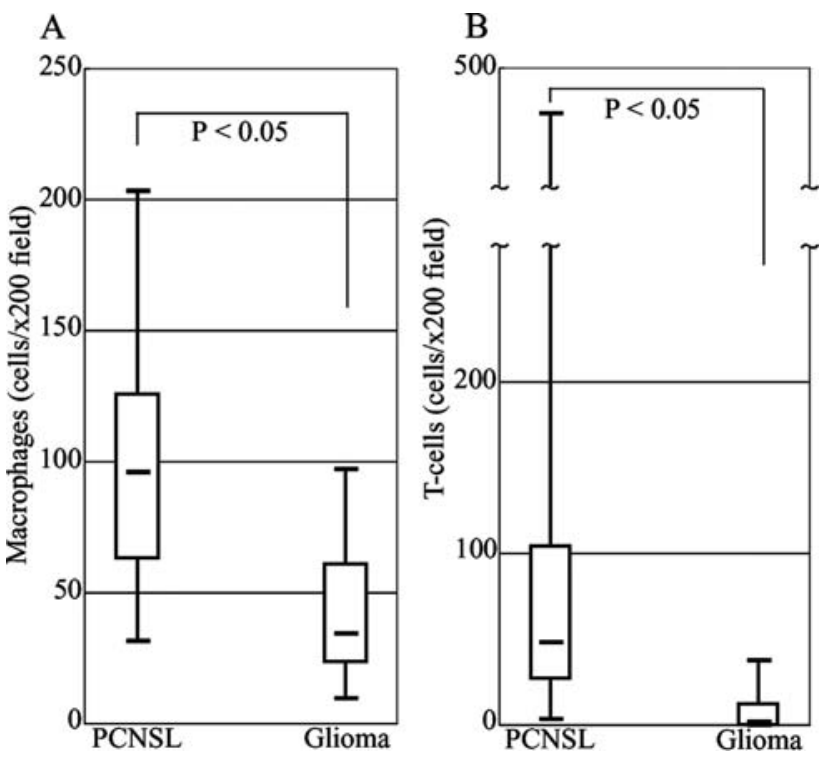

Figure 4. Plot box graphs representing the comparison in numbers of macrophages and T-cells around the tumor capillaries. Numbers of both macrophages (A) and T-cells (B) in PCNSL are significantly larger than those in glioma.

tumor cells (Fig. 3). The number of CD68-positive macrophages in PCNSL (median 95.9, range 31.7-203.7) was 2.3-fold higher than that of glioma (median 35.0, range 29.7-53.3) (Fig. 4A). Furthermore, we also found a considerable number of CD3-positive T-cells (median 47.9, range 3.7-473.3) in PCNSL, and this value was 5.9-fold higher than that of glioma (median 2.0, range 0.0-16.3) (Fig. 4B). These results raised the possibility of an inverse correlation between the number of these cells and the expression of MDRl Pgp and BCRP on the tumor capillary endothelial cells. No difference was found in the number of macrophages or T-cells among the three histological patterns of PCNSL or between the two grades of glioma (data not shown).

Expression of the ABC transporters in the tumor cells. Immunohistochemical analysis of the tumor cells in 22 PCNSL cases showed that, in 2 cases $(9 \%)$, a small number
Table III. Expression of the ABC transporters in tumor cells of PCNSL and glioma.

\begin{tabular}{lclc}
\hline & & \multicolumn{2}{c}{ Glioma } \\
\cline { 3 - 4 } & $\begin{array}{c}\text { PCNSL } \\
(\mathrm{n}=22)(\%)\end{array}$ & $\begin{array}{c}\text { Low grade } \\
(\mathrm{n}=9)(\%)\end{array}$ & $\begin{array}{c}\text { High grade } \\
(\mathrm{n}=21)(\%)\end{array}$ \\
\hline MDRl Pgp & & & \\
$3+$ & $0(0)$ & $0(0)$ & $0(0)$ \\
$2+$ & $0(0)$ & $0(0)$ & $0(0)$ \\
$1+$ & $2(9)$ & $0(0)$ & $5(5)$ \\
0 & $20(91)$ & $9(100)$ & $17(95)$ \\
BCRP & & & $0(0)$ \\
$3+$ & $0(0)$ & $0(0)$ & $0(0)$ \\
$2+$ & $0(0)$ & $0(0)$ & $0(0)$ \\
$1+$ & $0(0)$ & $0(0)$ & $21(100)$ \\
0 & $22(100)$ & $9(100)$ & $10(48)$ \\
MRP1 & & & $5(24)$ \\
$3+$ & $0(0)$ & $0(0)$ & $6(28)$ \\
$2+$ & $0(0)$ & $5(56)$ & $0(0)$ \\
$1+$ & $0(0)$ & $4(44)$ & $0(0)$ \\
0 & $22(100)$ & &
\end{tabular}

PCNSL, primary central nervous system lymphoma. Immunoreactivity was scored as: 0 , absent; $1+,<5 \%$ tumor cells reactive; $2+, 5-25 \%$ tumor cells reactive or $>25 \%$ tumor cells reactive at a weaker intensity than capillaries in the non-tumor brain; $3+$, $>25 \%$ tumor cells reactive at a comparable intensity to capillaries in the non-tumor brain.

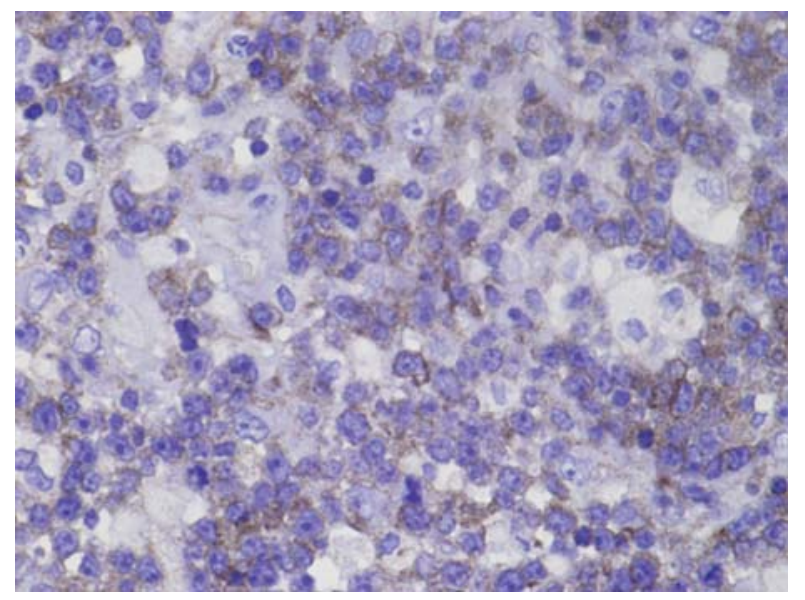

Figure 5. Immunohistochemistry of MDR1 Pgp in PCNSL. Gathering of an MDRl Pgp-positive subpopulation in PCNSL cells is shown. Magnification, x400.

of the tumor cells $(<5 \%$, score $1+)$ expressed detectable MDRl Pgp (Table III and Fig. 5). In contrast, expression of either BCRP or MRP1 was not observed in any of the PCNSL cases. Positive staining for MRP1 in the tumor cells was observed in all glioma cases, and the intensity of staining 
and expression rates were higher in high-grade tumors than in low-grade tumors (Table III). Of the 30 gliomas, 5 highgrade tumors contained a small number of MDRl Pgp-positive tumor cells $(<5 \%$, score $1+)$. Similar to PCNSL, expression of BCRP was not observed in any of the glioma cases.

\section{Discussion}

In this study, we demonstrate decreased expression of two major ABC transporters involved in BBB function, MDRl Pgp and BCRP, in tumor capillary endothelial cells of PCNSL. Another ABC transporter studied, MRP1, was not detected in any of the tumor capillary endothelial cells of PCNSL or in those of normal brain.

MDRl Pgp and BCRP are the major efflux transporters of the $\mathrm{BBB}$ that limit penetration of substrate drugs into the brain. On the other hand, the BBB also contains influx transporters such as organic anion polypeptide 1A2, which carry MTX (19). Decreased expression of MDRl Pgp and BCRP in tumor capillary endothelial cells of PCNSL may cause an efflux-influx imbalance and elevated tissue concentrations of MTX. In a clinical setting, Hiraga et al reported that the MTX concentration in cerebrospinal fluid (CSF) of PCNSL patients was higher than that of control leukemia patients (20).

From a microenvironment viewpoint, we can provide two explanations why expression of MDRl Pgp and BCRP decreases in the tumor capillary endothelial cells of PCNSL. First, interaction between astrocytes and capillaries may be interrupted by infiltration of tumor cells. Some investigators reported that expression and function of MDRl Pgp and BCRP in the capillaries were enhanced by contact with astrocytes and by astrocyte-derived soluble factor (12-14). In the present study, capillaries that lost contact with GFAPpositive astrocytes (in dense and perivascular patterns) showed decreased expression of MDRl Pgp and BCRP, whereas those having contact with astrocytes (in sparse patterns) exhibited preserved expression of these ABC transporters. Our results also emphasize the importance of astrocytes in the expression of MDRl Pgp and BCRP.

The second possible explanation is based on regulation by cytokines released from inflammatory cells. Recent studies have revealed that pro-inflammatory cytokines such as IL-6, IL- $1 B$ and TNF- $\alpha$ reduce the expression of ABC transporters, particularly BCRP, in endothelial cells $(15,16)$. We have shown here that PCNSL is accompanied by a considerably large number of major cytokine producers, macrophages and T-cells, compared to glioma. Infiltration of these cells may also be associated with decreased expression of the ABC transporters in PCNSL. Measurement of secreted cytokine levels using fresh frozen tissues is needed to validate this assumption.

Expression of ABC transporters in the tumor cells has been reported to be responsible for drug resistance in acute lymphoblastic leukemia (21), breast cancer (22), and nonsmall cell lung cancer (23). With regard to PCNSL, Kunishio et al proposed that expression of MDRl Pgp and MRP1 in tumor cells is associated with resistance to MTX (24). In this study, we analyzed the expression of the ABC transporters in tumor cells and found that MDRI Pgp alone was detected in only 2 of 22 cases. This result indicates that the low rate of ABC transporter expression in the tumor cells may be one of the factors associated with the high response rate of PCNSL to HD-MTX treatment.

Despite the high complete remission rate achieved with HD-MTX based chemotherapy, the disease relapses in 35$60 \%$ of patients in later years (25). All PCNSL cases examined here were diffuse large B-cell type. However, when we segregated the PCNSL cases according to their pattern of infiltration, heterogeneity was observed among the cases and even within a single tumor. In cases of areas with sparse patterns, expression of the ABC transporters in the tumor capillary endothelial cells may have been preserved and permeability of the drugs may have been kept to the lowermost levels in such areas. This implies that heterogeneity in the expression of the $\mathrm{ABC}$ transporters might be one of the reasons for the relapse of PCNSL after MTX treatment. A potential weakness of our study is that the PCNSL tissues used for immunohistochemical analysis were limited to small fragmented open-biopsy samples. Examination of autopsy cases that harbor a latent, untreated PCNSL may help to understand this spatial difference in the expression of $\mathrm{ABC}$ transporters within a tumor.

BBB function of capillary endothelial cells of the brain is achieved not only by the expression $\mathrm{ABC}$ transporters but also by the composition of tight junctions. Thus, decreased expression of the $\mathrm{ABC}$ transporters alone may not be sufficient for the significant increase in the penetration of MTX through the BBB. Clinical studies using osmotic BBB disruption, which opens endothelial tight junctions, has shown enhancement of the therapeutic effect of MTX in PCNSL patients (26). Understanding the BBB condition may facilitate the development of such novel therapeutic approaches for the treatment of PCNSL.

In conclusion, we demonstrate that the expression of the major ABC transporters of the BBB, MDR1 Pgp and BCRP, are decreased in tumor capillary endothelial cells of PCNSL. This decreased expression may determine the delivery of MTX to tumor tissues. Further studies towards understanding the $\mathrm{BBB}$ are needed to overcome the frequent relapse of PCNSL after MTX treatment.

\section{Acknowledgements}

We wish to thank Ms. Kaoruko Kojima for her excellent technical assistance.

\section{References}

1. Bhagavathi S and Wilson JD: Primary central nervous system lymphoma. Arch Pathol Lab Med 132: 1830-1834, 2008.

2. Hoang-Xuan K, Taillandier L, Chinot O, Soubeyran P, Bogdhan U, Hildebrand J, Frenay M, De Beule N, Delattre JY and Baron B; European Organization for Research and Treatment of Cancer Brain Tumor Group: Chemotherapy alone as initial treatment for primary CNS lymphoma in patients older than 60 years: a multicenter phase II study (26952) of the European Organization for Research and Treatment of Cancer Brain Tumor Group. J Clin Oncol 21: 2726-2731, 2003.

3. Batchelor T, Carson K, O'Neill A, Grossman SA, Alavi J, New P, Hochberg F and Priet R: Treatment of primary CNS lymphoma with methotrexate and deferred radiotherapy: a report of NABTT 96-07. J Clin Oncol 21: 1044-1049, 2003. 
4. Herrlinger U, Küker W, Uhl M, Blaicher HP, Karnath HO, Kanz L, Bamberg M and Weller M, Neuro-Oncology Working Group of the German Society: NOA-03 trial of high-dose methotrexate in primary central nervous system lymphoma: final report. Ann Neurol 57: 843-847, 2005.

5. Shibamoto Y, Ogino H, Suzuki G, Takemoto M, Araki N, Isobe K, Tsuchida E, Nakamura K, Kenjo M, Suzuki K, Hosono M, Tokumaru S, Ishihara S, Kato E, Ii N and Hayabuchi N: Primary central nervous system lymphoma in Japan: changes in clinical features, treatment, and prognosis during 1985-2004. Neuro Oncol 10: 560-568, 2008.

6. Löscher W and Potschka $\mathrm{H}$ : Blood-brain barrier active efflux transporters: ATP-binding cassette gene family. NeuroRx 2: 86-98, 2005

7. Persidsky Y, Ramirez SH, Haorah J and Kanmogne GD: Blood-brain barrier: structural components and function under physiologic and pathologic conditions. J Neuroimmune Pharmacol 1: 223-236, 2006.

8. Dauchy S, Dutheil F, Weaver RJ, Chassoux F, DaumasDuport C, Couraud PO, Scherrmann JM, De Waziers I and Declèves X: $\mathrm{ABC}$ transporters, cytochromes $\mathrm{P} 450$ and their main transcription factors: expression at the human bloodbrain barrier. J Neurochemistry 107: 1518-1528, 2008.

9. de Graaf D, Sharma RC, Mechetner EB, Schimke RT and Roninson IB: P-glycoprotein confers methotrexate resistance in $3 \mathrm{~T} 6$ cells with deficient carrier-mediated methotrexate uptake. Proc Natl Acad Sci USA 93: 1238-1242, 1996.

10. Vlaming ML, Pala Z, van Esch A, Wagenaar E, de Waart DR, van de Wetering K, van der Kruijssen CM, Oude Elferink RP, van Tellingen $\mathrm{O}$ and Schinkel AH: Functionally overlapping roles of Abcg2 (Bcrp1) and Abcc2 (Mrp2) in the elimination of methotrexate and its main toxic metabolite 7-hydroxymethotrexate in vivo. Clin Cancer Res 15: 3084-3093, 2009.

11. Borst P, Evers R, Kool M and Wijnholds J: A family of drug transporters: the multidrug resistance-associated proteins. J Natl Cancer Inst 92: 1295-1302, 2000

12. Hayashi Y, Nomura M, Yamagishi S, Harada S, Yamashita J and Yamamoto $\mathrm{H}$ : Induction of various blood-brain barrier properties in non-neural endothelial cells by close apposition to co-cultured astrocytes. Glia 19: 13-26, 1997.

13. Gaillard PJ, van der Sandt IC, Voorwinden LH, Vu D, Nielsen JL, de Boer AG and Breimer DD: Astrocytes increase the functional expression of P-glycoprotein in an in vitro model of the blood-brain barrier. Pharm Res 17: 1198-1205, 2000

14. Hori S, Ohtsuki S, Tachikawa M, Kimura N, Kondo T, Watanabe M, Nakashima E and Terasaki T: Functional expression of rat ABCG2 on the luminal side of brain capillaries and its enhancement by astrocyte-derived soluble factor(s). J Neurochem 90: 526-536, 2004 .

15. von Wedel-Parlow M, Wölte P and Galla HJ: Regulation of major efflux transporters under inflammatory conditions at the blood-brain barrier in vitro. J Neurochem 111: 111-118, 2009.

16. Poller B, Drewe J, Krähenbühl S, Huwyler J and Gutmann H: Regulation of BCRP (ABCG2) and P-glycoprotein (ABCB1) by cytokines in a model of the human blood-brain barrier. Cell Mol Neurobiol 30: 63-70, 2010.

17. Tóth K, Vaughan MM, Peress NS, Slocum HK and Rustum YM: MDR1 P-glycoprotein is expressed by endothelial cells of newly formed capillaries in human gliomas but is not expressed in the neovasculature of other primary tumors. Am J Pathol 149: 853-858, 1996
18. WHO Classification of Tumours of the Central Nervous System. 4th edition. Louis DN, Ohgaki H, Wiestler OD and Cavenee WK (eds). World Health Organization Classification of Tumours. IARC Press, Lyon, 2007.

19. Lee W, Glaeser H, Smith LH, Roberts RL, Moeckel GW, Gervasini G, Leake BF and Kim RB: Polymorphisms in human organic anion-transporting polypeptide 1A2 (OATP1A2): implications for altered drug disposition and central nervous system drug entry. J Biol Chem 280: 10-17, 2005.

20. Hiraga S, Arita N, Ohnishi T, Kohmura E, Yamamoto K, Oku Y, Taki T, Sato M, Aozasa K and Yoshimine T: Rapid infusion of high-dose methotrexate resulting in enhanced penetration into cerebrospinal fluid and intensified tumor response in primary central nervous system lymphomas. J Neurosurg 91: 221-230, 1999.

21. Styczynski J, Wysocki M, Debski R, Czyzewski K, Kolodziej B, Rafinska B, Kubicka M, Koltan S, Koltan A, Pogorzala M, Kurylak A, Olszewska-Slonina D, Balwierz W, Juraszewska E, Wieczorek M, Olejnik I, Krawczuk-Rybak M, Kuzmicz M, Kowalczyk J, Stefaniak J, Badowska W, Sonta-Jakimczyk D, Szczepanski T, Matysiak M, Malinowska I, Stanczak E, Wachowiak J, Konatkowska B, Gil L, Balcerska A and Maciejka-Kapuscinska L: Predictive value of multidrug resistance proteins and cellular drug resistance in childhood relapsed acute lymphoblastic leukemia. J Cancer Res Clin Oncol 133: 875-893, 2007.

22. Burger H, Foekens JA, Look MP, Meijer-van Gelder ME, Klijn JG, Wiemer EA, Stoter G and Nooter K: RNA expression of breast cancer resistance protein, lung resistance-related protein, multidrug resistance-associated proteins 1 and 2 , and multidrug resistance gene 1 in breast cancer: correlation with chemotherapeutic response. Clin Cancer Res 9: 827-836, 2003.

23. Berger W, Setinek U, Hollaus P, Zidek T, Steiner E, Elbling L, Cantonati H, Attems J, Gsur A and Micksche M: Multidrug resistance markers P-glycoprotein, multidrug resistance protein 1, and lung resistance protein in non-small cell lung cancer: prognostic implications. J Cancer Res Clin Oncol 131: 355-363, 2005.

24. Kunishio K, Okada M, Matsumoto Y and Nagao S: Preliminary individual adjuvant chemotherapy for primary central nervous system lymphomas based on the expression of drug-resistance genes. Brain Tumor Pathol 21: 57-61, 2004.

25. Reni M and Ferreri AJ: Therapeutic management of refractory or relapsed primary central nervous system lymphomas. Ann Hematol 80: 113-117, 2001.

26. Angelov L, Doolittle ND, Kraemer DF, Siegal T, Barnett GH, Peereboom DM, Stevens G, McGregor J, Jahnke K, Lacy CA, Hedrick NA, Shalom E, Ference S, Bell S, Sorenson L, Tyson RM, Haluska M and Neuwelt EA: Blood-brain barrier disruption and intra-arterial methotrexate-based therapy for newly diagnosed primary CNS lymphoma: a multi-institutional experience. J Clin Oncol 27: 3503-3509, 2009. 